\title{
Comparative Study of Efficacy and Safety of Diacerein versus Acelofenac in Patient with Knee Osteoarthritis
}

\author{
Sharma S, Rijal KP, Prasai T, Khanal H \\ Department of Orthopaedics, Kathmandu Medical College, Kathmandu, Nepal \\ Accepted: April 2, 2021 \\ Published: April 30, 2021 \\ Sharma S, Rijal KP, Prasai T, Comparative Study of Efficacy and Safety of Diacerein versus Acelofenac in Patient \\ with Knee Osteoarthritis. Nepal Journal of Medical Sciences. 2021;6(1):26-33. http://dx.doi.org/10.3126/njms.
}

Received: January 15, 2021

Cite this paper: v6i1.36729

\begin{abstract}
Introduction: There are different pharmacological modalities currently in practice for the treatment of osteoarthritis knee. Broadly these are divided into anti-inflammatory drugs such as NSAIDs and symptomatic slow-acting drugs in osteoarthritis (SYSADOA). Diacerein, an anthraquinone derivative inhibits IL-1b and has been shown to significantly decrease the symptoms.
\end{abstract}

Methods: This is open label, prospective comparative study. Total 40 patients were divided into two groups: group A (diacerein) and group B (aceclofenac) by alternate method. In group A diacerein was given $50 \mathrm{mg}$ orally for 1 week followed by $50 \mathrm{mg}$ orally twice a day for 3 weeks. In group B aceclofenac $200 \mathrm{mg}$ sustained release tablet was given orally once a day for 4 weeks. Outcomes were measured at the end of the treatment period i.e. at four weeks and after two weeks of discontinuation of treatment i.e. at 6 weeks.

Results: Improvement is observed in both treatment groups in their baseline value in terms of efficacy parameters. Results of VAS and WOMAC scores were better in group B (aceclofenac). However intra-group analysis showed VAS scores and WOMAC scores significantly decreased in patients receiving diacerein as well. $(\mathrm{p}<0.05)$.

Conclusion: Though not superior to the control drug, diacerein showed efficacy in terms of measurement by patient self-reported WOMAC and VAS scores for the treatment of osteoarthritis knee.

Keywords: Aceclofenac; Diacerein; Osteoarthritis Knee

Correspondence to: Dr. Sashmit Sharma

Department of Orthopaedics

Kathmandu Medical College

Kathmandu, Nepal

Email:sashmit_sharma@hotmail.com 


\section{INTRODUCTION}

Osteoarthritis (OA) is by far the most common form of joint disease throughout the world. ${ }^{1}$ The prevalence of symptomatic osteoarthritis of the knee occurs in $13 \%$ of female and $10 \%$ of male of sixty years of age and older. Joint pain is the dominant symptom of OA. ${ }^{2}$ Other common symptoms of knee osteoarthritis include pain, instability, swelling, stiffness and crepitus in the joint. There is diverse pathology in development of OA knee which includes focal damage and loss of articular cartilage, abnormal remodelling, attrition of subarticular bone, osteophytes formation, laxity of ligaments, synovial inflammation and cyst formation in the subchondral bone as well as periarticular muscle weakness. ${ }^{3,4}$ Synovial tissue cells and subchondral osteoblasts produce cytokines like IL-b and TNF a. These cytokines play key role in the catabolic process of cartilage degradation. ${ }^{5}$ The objectives of treatment in osteoarthritis knee are to reduce symptoms, to improve functional ability and to halt the progression of structural changes. Current treatment modalities of osteoarthritis include non-pharmacological, pharmacological therapies and surgery. Non pharmacological measures include patient education on daily activities modification and physiotherapy. Pharmacological therapy includes the use of analgesics and nonsteroidal anti-inflammatory drugs (NSAIDs) as well as symptomatic slow-acting drugs in osteoarthritis (SYSADOA). Surgical treatments includes various orthopaedic surgery such as arthoplasty, arthodesis etc. Non-steroidal anti-inflammatory drugs (NSAIDS) have long been the preferred therapy for relief of pain and stiffness related to arthritic joints, because of their analgesic and anti-inflammatory properties, although their use in this condition has sparked controversy. ${ }^{6}$ Though use of NSAIDs provide the symptomatic relief they do not play role in the reversal of basic pathology of Osteoarthritis instead they may flare up the disease processes like degeneration of cartilage, inhibition of chondroitin synthesis and suppression of proteoglycan synthesis by chondrocyte. ${ }^{7}$ Among NSAIDs, aceclofenac has been established as a safe and effective medicine due to its superior selectivity for COX-2 inhibition. ${ }^{8}$ Since the inflammation in knee OA is primarily due to the presence of the cytokine interleukin-1b (IL-1b), diacerein, an anthraquinone derivative inhibits IL-1b and has been shown to significantly decrease the symptoms. ${ }^{9}{ }^{10}$ In addition, studies have shown that diacerein has proven analgesic efficacy comparable to that of diclofenac in patients with OA knee. ${ }^{11}$ As patient satisfaction is not so optimal with current commonly use drugs and most of the drugs used for treatment (eg. NSAIDS) only provides symptomatic relief, this study aims to see if the use of diacerein will be proven as alternative and efficient drug in the management of OA knee.

\section{METHODS}

\section{Study design and sample size}

This open label, prospective comparative study is conducted in accordance with Declaration of Helsinki ${ }^{12}$. The protocol of this study was approved by institutional review committee of Kathmandu Medical College Teaching Hospital, Sinamangal, Kathmandu. Total 40 patients were included in the study after obtaining the informed consent.

\section{Study setting}

Patients were recruited from Orthopaedic outpatient department of Kathmandu Medical College Teaching Hospital, Sinamangal, Kathmandu.

\section{Exclusion and inclusion criteria}

The inclusion criteria were set as symptomatic patients between 40 to 70 years of age who fits in the criteria of American College of Rheumatology for OA knee with a radiologic score of II or III on the Kellgren/Lawrence grading for OA knee. ${ }^{13,14}$ Similarly, exclusion criteria were history of surgery around knee or hip joints, history of significant knee injury, accompanying hip OA, previous intra-articular injection in past 3 months, inflammatory disease of knee, oral 
treatment with a symptomatic slow-acting OA drug (chondroitin sulfate, glucosamine sulfatediacerein, piascledine) within 4 months prior to start of the study, severe systemic disease, severe gastrointestinal disorders, persistent diarrhea (alteration in stool consistency and increase in frequency of more than 4 weeks duration) or laxative use, Pregnancy (also who are planning the pregnancy during the study) and lactation, hypersensitivity to aceclofenac, diacerein or similar compounds. Patient with deranged renal function test, chronic hepatic disease and those who refused to give informed consent were also excluded from the study.

\section{Treatment procedure}

Patients who met the inclusion criteria were selected for the study after signing the informed consent. Patients were put in two groups Group A (Diacerin) and Group B (Aceclofenac) by alternate method. Before prescribing the drugs thorough history, physical examination and baseline haematological and biochemistry investigation were done in both the groups. In Group A diacerein $50 \mathrm{mg}$ was given for first 1 week followed by diacerein $50 \mathrm{mg}$ twice a day orally for 3 weeks. In group B aceclofenac 200 $\mathrm{mg}$ sustained release once daily orally was given for 1 month. In addition rabeprazole 20 mg once daily was given to group B to reduce upper gastrointestinal side effects. Paracetamol tablet $1 \mathrm{gm}$ was prescribed to both groups if pain becomes severe as a rescue medicine. Physiotherapy in the form of quadriceps strengthening exercises was allowed in both groups. After the initial evaluation the patients were followed up at 1 month in hospital and at 45 days in either hospital or phone follow up as per patient's compliance.

\section{Efficacy parameters}

The efficacy is measured by using Western Ontario and McMaster Universities Arthritis Index (WOMAC) which has three sub-score for pain, stiffness and physical function ${ }^{15}$ and visual analogue scale score for pain (VAS). Both score were evaluated on the first day of treatment and at 1 month. At 45 days again
WOMAC and VAS score were evaluated to see the carryover effects of the drugs. We planned to include need of using rescue medication (i.e. Tablet Paracetamol) as efficacy parameter but we did not include it because most of the patients usually failed to remember the exact amount of rescue medication they consumed within a month.

\section{Safety parameters}

Patients in both groups were thoroughly examined and detailed history was taken to find out any existing illness. Vital signs were checked up in every follow up. Laboratory blood investigations were done as baseline at the start of the study and after 30 days. In addition to these investigations in group B, serum urea and creatinine were evaluated at least once between the baseline and final follow up. The compliance was evaluated by self-reported adherence method by asking patient to report the number of days or doses they have missed.

\section{Statistical analysis}

The collected data was charted on Microsoft excel 2013.The patient characteristics (Age, Height, Weight, etc.) were recorded on baseline visit. Quantitative data was expressed in terms of mean and standard deviation. The efficacy of treatment between the two groups was evaluated using "independent sample t test". The carryover effect of each drug was analysed using "paired sample t test". Statistical package for social science (SPSS) was used for the analysis of data.

\section{RESULTS}

Total 40 patients, who completed the study (20 in each group) were analysed. Demographic characteristics of both groups were found to be comparable. Majority of patients are female which accounts for $82.5 \%$ of the study population. They are comparably distributed between two groups; 17 in diacerin group and 16 in aceclofenac group, respectively. In accordance with inclusion criteria patients with K-L grade II and III knee osteoarthritis were included in the study (Table 1). 
Table 1: Demographic characteristics of study population

\begin{tabular}{|c|c|c|}
\hline Variable & $\begin{array}{l}\text { Diacerein group } \\
\qquad(\mathrm{N}=\mathbf{2 0})\end{array}$ & $\begin{array}{l}\text { Aceclofenac group } \\
\qquad(\mathrm{N}=\mathbf{2 0})\end{array}$ \\
\hline Age in years & $51.30 \pm 6.23$ & $57.15 \pm 8.82$ \\
\hline $\operatorname{Sex}(F: M)$ & $17: 3$ & $16: 4$ \\
\hline BMI & $28.10 \pm 3.93$ & $26.56 \pm 2.43$ \\
\hline K-L grade & $\begin{array}{l}\text { K-L grade II :11 } \\
\text { K-L grade III :09 }\end{array}$ & $\begin{array}{l}\text { K-L grade II :12 } \\
\text { K-L grade III :08 }\end{array}$ \\
\hline $\begin{array}{l}\text { VAS at } \\
\text { baseline } \\
\text { (10mm scale) }\end{array}$ & $7.05 \pm 0.944$ & $6.40 \pm 0.940$ \\
\hline WOMAC at baseline & $42.85 \pm 8.54$ & $42.40 \pm 6.79$ \\
\hline
\end{tabular}

The mean age of patient in diacerein group is 51.30 with SD of 6.23 and 57.15 with SD of 8.82 in aceclofenac group. The baseline BMI of two groups are also comparable; $28.10 \pm$ 3.93 in diacerein group and $26.56 \pm 2.43$ in aceclofenac group.

The correlation between different variables is also calculated using the Pearson's Coefficient of Correlation. There is positive correlation between body mass index at baseline with baseline WOMAC and VAS score with coefficient of co-relation 0.264 and 0.273 respectively. The correlation between WOMAC and VAS score is significant with the co-efficient of co-relation $0.665(\mathrm{p}<0.01)$. The efficacy of drugs is measured in terms of comparing mean values of WOMAC and VAS score. At 1 month there is significant difference in VAS score between the two groups $(p<0.05)$. The VAS score difference between two groups at baseline was $0.6 \mathrm{~mm}$ $(7.05 \pm 0.94$ in diacerein arm and $6.4 \pm 0.94)$ whereas at the end of one month it was $1.1 \mathrm{~mm}$ (4.2 \pm 0.76 in diacerein arm and 3.15 \pm 0.93$)$. At 45 days the difference in VAS score between the two groups is not significant $(p>0.05)$. (Table 2) The mean WOMAC scores at baseline were comparable between two groups (42.85 \pm 8.54 in diacerein arm and $42.40 \pm 6.79$ in aceclofenac arm). At 1 month follow up the mean WOMAC score in diacerein group is 28.8 \pm 6.96 and $24.1 \pm 5.34$ in aceclofenac group which was significant difference with $p$ value of less than 0.05 . Superiority of aceclofenac is seen in terms of VAS and WOMAC scores at 1 month. WOMAC sub-scores between two groups were not significant except WOMAC sub score for physical function at one month $(\mathrm{p}<0.05)$. (Table 3$)$

\section{Table 2: VAS score in two groups $(10 \mathrm{~mm}$} scale)

\begin{tabular}{lccl}
$\begin{array}{l}\text { Follow } \\
\text { up visit }\end{array}$ & $\begin{array}{c}\text { Diacerein } \\
\text { group }\end{array}$ & $\begin{array}{c}\text { Aceclofenac } \\
\text { group }\end{array}$ & $\begin{array}{c}\text { p- } \\
\text { value }\end{array}$ \\
Day 0 & $7.05 \pm 0.944$ & $6.40 \pm 0.940$ & 0.035 \\
Day 30 & $4.20 \pm 0.768$ & $3.15 \pm 0.933$ & 0.0003 \\
Day 45 & $5.30 \pm 1.218$ & $5.30 \pm 1.417$ & 1.00 \\
\hline
\end{tabular}

When within group analysis was done the result showed that the increase in VAS score by $26.19 \%$ and WOMAC score by $19.27 \%$ in diacerein group and VAS score by $67.18 \%$ and WOMAC score by $46.27 \%$ in aceclofenac group when compared the value at 1 month and 45 days. This shows the carry-over effect of diacerein is superior to that of aceclofenac. Patient in both groups didn't report any serious adverse effect. We relied on patient reported any new symptoms or problem after initiation of treatment. Laboratory blood investigation was comparable in both groups at baseline and after completion of study. The self-reported adherence method was 
opted for the compliance of the drug and all patient claimed they have taken all medicine as prescribed so compliance was considered $100 \%$ for both groups but the patients in both group were unable to recall the exact dose of rescue medication used by them hence it was considered as no use of rescue medication on both group.

Table 3: WOMAC score in two groups at baseline, 30 and 45 days

\begin{tabular}{lllll}
\multicolumn{1}{c}{ WOMAC SCORES } & $\begin{array}{c}\text { Follow up } \\
\text { visit }\end{array}$ & $\begin{array}{c}\text { Diacerein group } \\
(\mathrm{N}=20)\end{array}$ & $\begin{array}{c}\text { Aceclofenac group } \\
(\mathrm{N}=20)\end{array}$ & P-value \\
\hline WOMAC (pain) & Day 0 & $8.45 \pm 1.79$ & $8.50 \pm 1.54$ & 0.925 \\
& Day 30 & $5.2 \pm 1.39$ & $4.75 \pm 1.02$ & 0.556 \\
& Day 45 & $5.75 \pm 2.19$ & $6.75 \pm 1.77$ & 0.885 \\
WOMAC(stiffness) & Day 0 & $4.65 \pm 1.49$ & $4.40 \pm 1.14$ & 0.252 \\
& Day 30 & $2.55 \pm 0.99$ & $2.10 \pm 1.02$ & 0.167 \\
& Day 45 & $3.20 \pm 1.32$ & $3.20 \pm 1.24$ & 0.014 \\
WOMAC & & & & \\
function) & & & & \\
& Day 0 & $29.75 \pm 5.99$ & $29.5 \pm 4.82$ & 0.122 \\
& Day 30 & $21.35 \pm 5.22$ & $17.65 \pm 3.78$ & 1.00 \\
WOMAC(Total) & Day 45 & $25.40 \pm 6.69$ & $25.30 \pm 5.97$ & 0.961 \\
& & & & \\
& Day 0 & $42.85 \pm 8.53$ & $42.40 \pm 6.78$ & 0.855 \\
& Day 30 & $28.80 \pm 6.96$ & $24.10 \pm 5.34$ & 0.022 \\
& Day 45 & $34.35 \pm 9.48$ & $35.25 \pm 8.28$ & 0.751 \\
\hline
\end{tabular}

\section{DISCUSSION}

The current modalities of treatment for osteoarthritis of knee consists mainly the pharmacological treatment with aid of nonpharmacological measures such as patient education and physiotherapy. NSAIDs are widely accepted and used drugs in treatment of Osteoarthritis symptomatic management. Studies have shown that Interlukin-1B involvement in molecular level in pathogenesis of osteoarthritis. ${ }^{5}$ Diacerein acts by inhibiting the interlukin-1B by reducing the interlukin$1 \mathrm{~B}$ converting enzyme as well as by reducing the sensitivity of interlukin-1B as it decreases the interlukin-1 receptor on cell surface of chondrocyte. ${ }^{9,16}$ In recent times multiple researches are being done to retard the basic pathology (i.e. progressive degeneration of articular cartilage).

Regarding the demographic result of this study; the average age in this study is $54.23 \pm$
8.904. This is lower than the studies conducted by Pavelka et al. in Europe where average age was 63.8 years, Pelletier et al. in Israel and Canada where average age was 63.5 years and Zheng et al. in China where average age was 58.85 years. ${ }^{11,17,18}$ Age was comparable with studies conducted in Indian population. ${ }^{19,20}$. The average BMI in this study is 27.33 which is lower than the other studies this could be due to the fact that $45 \%$ of study population are farmer by occupation.

At the end of 1 month treatment period the reduction of the VAS and WOMAC scores was better in aceclofenac group. However there is decrease of VAS and WOMAC score by $40.04 \%$ and $32.78 \%$ in diacerein group at the end of 1 month suggesting the efficacy of diacerein as well. Palvelka et al. control trial shows the reduction of WOMAC score by $18.86 \%$ in his study in diacerein group and Singh et al. studies shows reduction of VAS score by $32.97 \%$ and WOMAC score 
by $15.04 \%$ at 3 weeks in diacerein group in his study. ${ }^{17,19}$ In within group analysis the increase in VAS and WOMAC scores are comparatively lower in diacerein group when compared at 45 days which signifies the carryover effect of diacerein which has been also shown in other studies. ${ }^{17,19,21}$ As aceclofenac is established treatment in view of safety and efficacy in this study it has been used as control to evaluate the efficacy of diacerein. ${ }^{22}$ In our study no serious adverse effect has been recorded. Patients in diacerein group reported the yellow discoloration of urine and loose stool (less than 3 episode per day). Discolouration of urine is due to elimination of diacerein metabolite from urine which has no clinical consequences hence not recorded a side-effect. ${ }^{23}$ Furthermore in this study rabeprazole $20 \mathrm{mg}$ per day was prescribed to the patient in aceclofenac group which may have reduced the upper gastrointestinal sideeffect related to aceclofenac.

This open label, comparative study with small study population of 40 patients is one of the limitations of this study. Other limitation of the study is duration of study which was total of 45 days. The use of rescue medication couldn't be calculated and compliance was considered $100 \%$ as patients reported that way which may have been influenced by recall bias. This is another limitation of study. Rather than self-reporting of adverse events leading questionnaire with thorough systemic examination would have been better for analysis of safety. Furthermore the tools we used to measure efficacy WOMAC and VAS score are based on patient's self-reporting. Utilization of performance based tools would have been better for the measure of efficacy.

\section{CONCLUSION}

Though not superior to the control drug, diacerein showed efficacy in terms of measurement by patient self-reported WOMAC AND VAS scores for the treatment of Osteoarthritis knee (KL-GRADING II AND III). Diacerein also showed significant carryover effect in our study. Taking consideration that our study is open label, comparative with small study population, the result of our study should be verified by Multi-central randomized control trial involving large study population with longer duration of study in Nepalese population.

\section{CONFLICT OF INTEREST}

None

\section{SOURCES OF FUNDING}

None

\section{REFERENCES}

1. Dieppe P, Bloom A. Osteoarthritis. In: Solomon A, Warwick D, Nayagam S, editors. Apley's system of orthopaedics and fractures. $10^{\text {th }}$ ed. Boca Raton: $\mathrm{CRC}$ press; 2017:90-107.

2. Zhang Y, Jordan JM. Epidemiology of Osteoarthritis. Clin Geriatr Med. 2010;26(3):355-69. https://doi. org/10.1016/j.cger.2010.03.001

3. Pelletier J, Martel-pelletier J, Abramson SB. Osteoarthritis, an Inflammatory Disease Potential Implication for the Selection of New Therapeutic Targets. Arthritis Rheum. 2001;44(6):1237$47 . \quad$ https://doi.org/10.1002/15290131(200106)44:6\%3C1237::AIDART214\%3E3.0.CO;2-F

4. Pelletier JP, Martel-Pelletier J. Therapeutic targets in osteoarthritis: from today to tomorrow with new imaging technology. Ann Rheum Dis. 2003;62(suppl 2):ii7982. $\quad$ https://doi.org/10.1136/ard.62. suppl 2.ii79

5. Aigner T, Soeder S, Haag J. IL-1 $\beta$ and BMPS - Interactive players of cartilage matrix degradation and regeneration. Eur Cells Mater. 2006;12:49-56. https://doi. org/10.22203/eCM.v012a06

6. Dingle J. Cartilage maintenance in osteoarthritis: Interaction of cytokines, NSAID and prostaglandins in articular cartilage damage and repair. $J$ Rheumatol Suppl. 1991;28:30-7. Available From: http://pascal-francis.inist.fr/vibad/ index.php?action $=$ getRecordDetail\& 
$\underline{\mathrm{idt}=5286013}$ [Accessed 3rd February 2021]

7. Brandt KD. Effects of nonsteroidal antiinflammatory drugs on chondrocyte metabolism in vitro and in vivo. $\mathrm{Am}$ J Med. 1987;83(5):29-34. https://doi. org/10.1016/0002-9343(87)90848-5

8. Solanki S, Dahima R. Formulation and evaluation of aceclofenac mouthdissolving tablet. J Adv Pharm Technol Res. 2011;2(2):128-31. https://doi. org/10.4103/2231-4040.82951

9. Martel Pelletier J, Pelletier JP. Effects of diacerein at the molecular level in the osteoarthritis disease process. Ther Adv Musculoskelet Dis. 2010;2(2):95-104. https://doi. org/10.1177/1759720X09359104

10. Bartels EM, Bliddal H, Schøndorff PK, Altman RD, Zhang W, Christensen R. Symptomatic efficacy and safety of diacerein in the treatment of osteoarthritis: a meta-analysis of randomized placebo-controlled trials. Osteoarthr Cartil. 2010;18(3):289-96. https://doi. org/10.1016/j.joca.2009.10.006

11. Zheng W, Tang F, Li J, Zhang F, Li Z, Su $Y$ et al. Efficacy and safety of diacerein in osteoarthritis of the knee : controlled trial in China. APLAR Journal of Rheumatology. 2006;9(1)64-9. https://doi. org/10.1111/j.1479-8077.2006.00167.x

12. World Medical Association declaration of Helsinki: Ethical principles for medical research involving human subjects. JAMA. 2013;310(20):2191-4. https:// doi:10.1001/jama.2013.281053

13. Altman R, Asch E, Bloch D, Bole G, Borenstein D, BrandtK etal. Development of criteria for the classification and reporting of osteoarthritis: classification of osteoarthritis of the knee. Arthritis \& Rheumatism: Official Journal of the Arthritis Rheum. 1986;29(8):1039-49. https://doi.org/10.1002/art.1780290816

14. Kellgren JH, Lawrence JS. Radiological assessment of osteo-arthrosis. Ann Rheum Dis. 1957;16(4):494-502. https:// doi.org/10.1136/ard.16.4.494
15. Bellamy N, Buchanan WW, Goldsmith $\mathrm{CH}$, Campbell J, Stitt LW. Validation study of WOMAC: a health status instrument for measuring clinically important patient relevant outcomes to antirheumatic drug therapy in patients with osteoarthritis of the hip or knee. $J \quad$ Rheumatol. 1988;15(12):1833-40. Available from: https://psycnet.apa.org/ record/2019-29410-001 [Accessed 13th February 2021]

16. Martel-Pelletier J, Mineau F, Jolicoeur FC, Cloutier JM, Pelletier JP. In vitro effects of diacerhein and rhein on interleukin 1 and tumor necrosis factor-alpha systems in human osteoarthritic synovium and chondrocytes. J Rheumatol. 1998 ;25(4):753-62.Available from: https:// europepmc.org/article/med/9558181 [Accessed 23rd February 2021]

17. Pavelka K, Trč T, Karpaš K, Vítek $P$, Sedláčkovă M, Vlasáková V et al. The efficacy and safety of diacerein in the treatment of painful osteoarthritis of the knee: A randomized, multicenter, doubleblind, placebo-controlled study with primary end points at two months after the end of a three-month treatment period. Arthritis Rheum. 2007;56(12):4055-64. https://doi.org/10.1002/art.23056

18. Pelletier J, Yaron M, Haraoui B, Cohen P, Nahir MA, Choquette D et al. Efficacy and safety of diacerein in osteoarthritis of the knee. Arthritis Rheum. 2000;43(10):233948. $\quad$ https://doi.org/10.1002/15290131(200010)43:10\%3C2339::AIDANR23\%3E3.0.CO;2-P

19. Singh K, Sharma R, Rai J. Diacerein as adjuvant to diclofenac sodium in osteoarthritis knee. Int $J$ Rheum Dis. 2012;15(1):69-77. $\quad$ https://doi. org/10.1111/j.1756-185X.2011.01648.X

20. Gayathri CR, Vanitha S, Felix JW, Nirmala P. Comparative analysis of efficacy and safety of diacerein versus s-adenosyl methionine in the management of osteoarthritis of knee joint. Int J Chem Pharm Res. 2017;9(6):46-51. https://doi. org/10.22159/ijcpr.2017v9i6.23428 
21. Louthrenoo W, Nilganuwong S, Aksaranugraha S, Asavatanabodee $\mathrm{P}$, Saengnipanthkul S, the Thai Study Group. The efficacy, safety and carryover effect of diacerein in the treatment of painful knee osteoarthritis: a randomised, double-blind, NSAID-controlled study. Osteoarthr Cartil. 2007;15(6):605$14 . \quad$ https://doi.org/10.1016/j. joca.2007.02.021

22. Patel PB, Patel TK. Efficacy and safety of aceclofenac in osteoarthritis: A metaanalysis of randomized controlled trials. Eur J Rheumatol. 2017;4(1):11-8. https:// doi.org/10.5152/eurjrheum.2017.160080

23. Michon M, Sellam J, Berenbaum F. Management of Osteoarthritis: Pharmacotherapy. Targeted treatment of the rheumatic disease. Weisman $\mathrm{MH}$, Weinblatt ME, Louie JS, Van Vollenhoven R. Saunders, Philadelphia. 2010:303-16. https://doi.org/10.1016/B978-1-41609993-2.00023-0 